\title{
Perancangan Pembangkit Listrik Termoelektrik pada Proses Refrigerasi Air Conditioner dengan Metode Fuzzy Logic
}

\section{AHMAD SETIAWAN ${ }^{1}$, NAZORI AGANI ZAKARIA ${ }^{1 *}$, AKHMAD MUSAFA ${ }^{*}$, SUJONO ${ }^{1,2}$}

\author{
${ }^{1}$ Teknik Elektro, Fakultas Teknik, Universitas Budi Luhur, Indonesia \\ 2Pusat Studi Mobil Listrik, Universitas Budi Luhur, Indonesia \\ Email: ahmadsetiawanmtc@gmail.com, *nazori@budiluhur.ac.id, \\ *akhmad.musafa@budiluhur.ac.id *corresponding author
}

Received 5 Oktober 2020| Revised 30 November 2020| Accepted 25 Desember 2020

\begin{abstract}
ABSTRAK
Pada penelitian ini dibahas tentang pembangkit listrik termoelektrik pada refrigerasi air conditioner. Bagian sistem terdiri dari air conditioner yang sudah dimodifikasi dengan menambahkan 50 buah modul termoelektrik dengan kontroler. Penggunaan termoelektrik bertujuan merubah suhu panas dan dingin pada air conditioner kedalam bentuk listrik. Tegangan yang dihasilkan termoelektrik dikontrol dengan metode fuzzy logic dengan parameter masukan nilai error dan delta error serta keluaran fuzzy berupa duty cycle yang mengatur switching dari DC-DC Converter. Hasil yang didapatkan pada penelitian ini, air conditioner dapat dimanfaatkan untuk pembangkit listrik termoelektrik dengan tegangan open circuit termoelektrik dapat mencapai 14 Volt saat delta temperatur $32,38^{\circ} \mathrm{C}$. Hasil pengujian dengan kontroler fuzzy diperoleh respon sistem dengan delay time 6 menit 18 detik, rise time 5 menit 51 detik, steady state error 0,8 pada set poin 7,2 Volt. Tegangan yang dihasilkan termoelektrik generator dapat digunakan untuk pengisian aki dengan arus pengisian 0,33 mA.
\end{abstract}

Kata kunci: Termoelektrik Generator, Peltier, Air Conditioner, Logika Fuzzy, HVAC

\begin{abstract}
This research discusses the thermoelectric power generation in the air conditioner refrigeration process. The system consists of air conditioner that has been modified by adding 50 thermoelectric and controller. The voltage generated by the thermoelectric is controlled by the fuzzy logic method with input parameters of error, delta error values, and the output fuzzy is a duty cycle that will regulate voltage of DC-DC Converter. The results obtained in this research, air conditioner can be used for thermoelectric power generation with open circuit voltage without control can reach 14 Volts when the delta temperature is $32.38^{\circ} \mathrm{C}$. The results with fuzzy control system obtained response system with a delay time of 6 minutes 18 seconds, rise time 5 minutes 51 seconds, steady state error 0.8 at set point of 7.2 volts. The voltage generated by the thermoelectric generator can be used to charge the battery with a charging current of $0.33 \mathrm{~mA}$.
\end{abstract}

Keywords: Thermoelectric Generator, Peltier, Air Conditioner, Fuzzy Logic, HVAC 


\section{PENDAHULUAN}

Pada dunia industri banyak digunakan sebuah sistem pendingin skala besar seperti air conditioner, chiller, dan frezzer untuk kebutuhan pendingin ruangan maupun untuk penyimpanan bahan makanan. Sistem refrigerasi pada air conditioneryang banyak digunakan adalah sistem refrigerasi kompresi uap. Pada sistem refrigerasi kompresi uap menggunakan peralatan mekanikal berupa mesin kompresor yang dapat menghasilkan energi panas. Energi panas pada sistem refrigerasi kompresi uap diperoleh melalui kompresor pada saat melakukan proses kompresi bahan pendingin (refrigeran)(Majanasastra, 2015). Selama ini air conditioner hanya dimanfaatkan udara dinginnya saja, sedangkan panas buangannya lebih banyak dibuang kelingkungan. Ada penelitian tentang kajian potensi energi panas buangan air conditioner dengan kapasitas pendinginan $9000 \mathrm{Btu} / \mathrm{hr}$. Pada penelitian tersebut didapatkan bahwa temperatur yang keluar dari kondensor rata-rata adalah $44,47^{\circ} \mathrm{C}$ dan temperatur udara maksimal yang keluar adalah $53,50^{\circ} \mathrm{C}$, sedangkan kalor yang dilepaskan kondensor sebesar 0,84 kW (Hermawan \& Idris, 2014).

Generator termoelektrik didasarkan pada sebuah efek yang disebut efek seebeck. Fenomena seebeck effect ini pertama kali ditemukan oleh ilmuan Jerman yaitu Thomas Jhohan Seebeck pada tahun 1821. Thomas Seebeck mencoba menggabungkan tembaga dan besi pada satu rangkaian kemudian tembaga dan besi tersebut diletakkan sebuah jarum kompas dan pada salah satu sisi logam tersebut dipanaskan lalu jarum kompas pun bergerak. Fenomena tersebut menandakan bahwa timbul medan listrik pada kedua logam tersebut akibat dipanaskan pada salah satu sisinya (Zhang \& Zhao, 2015). Modul termoelektrik (peltier) dapat digunakan sebagai elemen pendingin maupun sebagai generator. Modul termoelektrik terdiri dari susunan $\mathrm{N}$ dan $\mathrm{P}$ semikonduktor yang dapat menerima sumber panas dari sisi panasnya, dan sisi dinginnya diberi pendingin (heatsink), dengan perbedaan temperatur pada kedua sisi nya dapat menghasilkan energi listrik. Dan energi listrik dapat mengonversi termoelektrik menjadi elemen pendingin maupun pemanas dengan merubah arah polaritas arus listrik (Zheng, Liu, Yan, \& Wang, 2014).

Energi termal yang dihasilkan dari kondensor air conditioner dapat dimanfaatkan menjadi energi listrik dengan menambahkan saluran udara (duct) dengan insulasi dan modul termoelektrik generator (Ryanuargo, Anwar, \& Sari, 2013). Insulasi saluran udara dapat menggunakan jenis rockwool dan glasswool. Daya listrik rata-rata yang dihasilkan termoelektrik generator dari panas kondensor dengan insulasi rockwool lebih besar dari pada glasswool(Sari, 2019).

Pada termoelektrik generator harus terjadi perbedaan suhu pada kedua sisinya. Sisi panas termoelektrik generator dapat disimulasikan menggunakan elemen heater. Sisi dingin termoelektrik dapat ditambahkan sebuah heatsink untuk transfer panas yang diserap modul termoelektrik pada sisi panasnya. Pada heatsink dapat digunakan kipas dengan kecepatan bervariasi. Peningkatan aliran udara pada heatsink menyebabkan transfer panas pada termoelektrik lebih baik dan menyebabkan daya keluaran generator termoelektrik yang lebih optimal(Remeli, dkk, 2015). Selain heatsink sisi dingin pada termoelektrik generator dapat digunakan sebuah water block. Dimana tegangan termoelektrik generator yang dihasilkan dapat digunakan untuk pengisian sebuah aki (Puspita, Sunarno, \& Indarto, 2017).

Pada paper (Negash, Kim, \& Cho, 2017) dilakukan penelitian tentang termoelektrik generator dengan konfigurasi susunan termoelektrik secara seri, paralel, dan kombinasi. Hasilnya output daya termoelektrik generator menurun dengan meningkatnya jumlah percabangan sirkuit termoelektrik generator. Konfigurasi susunan seri menunjukkan pembangkitan daya hingga 94\%, sedangkan konfigurasi susunan campuran dengan enam 
Perancangan Pembangkit Listrik Termoelektrik pada Proses Refrigerasi Air Conditioner dengan Metode Fuzzy Logic

persimpangan dihasilkan hanya $62,5 \%$ dibandingkan dengan output daya referensi. Output daya dari TEG menurun dengan meningkatnya jumlah modul yang tidak seimbang dalam sirkuit. Pembangkitan daya konfigurasi susunan parallel TEG dengan jumlah modul yang seimbang mencapai 95,4\%, sedangkan susunan paralel dengan empat jumlah modul yang tidak seimbang dalam susunan hanya menghasilkan 58,9\%. Sehingga didapatkan konfigurasi susunan dengan jumlah persimpangan yang diminimalkan dan jumlah modul termoelektrik yang seimbang, direkomendasikan untuk memaksimalkan output daya termoelektrik generator.

Salah satu metode kontrol tegangan keluaran termoelektrik generator yang dapat digunakan adalah metode fuzzy logic. (Sreekala \& Ramkumar, 2019) melakukan penelitian mengenai perbandingan performa tegangan keluaran termoelektrik generator menggunakan kontroller PI, PID dan fuzzy logic. Dari hasil simulasi matlab didapakan bahwa metode fuzzy logic controller mendapatkan hasil performa yang lebih baik dibandingkan kontoller PI, maupun PID.

Penelitian yang telah dilakukan untuk pengujian termoelektrik generator pada umumnya menggunakan elemen heater dengan penambahan heatsink dan kipas. Dimana daya yang dikeluarkan dari elemen heater dan kipas tidak sebanding dengan tegangan output termoelektrik generator. Sehingga penggunaan termoelektrik generator lebih baik jika menggunakan panas yang terbuang dari proses industri seperti panas yang terbuang pada air conditioner. Namun pada penelitian sebelumnya panas yang diambil pada air conditioner merupakan panas hasil buangan uap kondensor pada air conditioner, bukan dari panas proses kompresi kompresor pada air conditioner.

Berdasarkan hal tersebut dibuat sebuah pembangkit listrik termoelektrik pada sistem refrigerasi air conditioner. Pada penelitian ini menggunakan modul termoelektrik TEC 12706 sebanyak 50 buah secara seri. Berbeda dengan penelitian sebelumnya, termoelektrik generator akan memanfaatkan suhu panas dari discharge line dari proses kompresi kompresor pada air conditioner, dan memanfaatkan suhu dingin suction line dari sisa proses pendinginan ruangan. Tegangan output yang dihasilkan dari termoelektrik generator tersebut diatur menggunakan algoritma fuzzy logic dengan menggunakan DC-DC konverter agar didapatkan tegangan output yang lebih stabil. Tegangan output DC-DC konverter digunakan untuk mengisi sebuah baterai (aki) secara otomatis.

\section{PERANCANGAN SISTEM}

\subsection{Perancangan Perangkat Keras}

Perancangan perangkat keras pembangkit listrik termoelektrik pada proses refrigerasi air conditioner dengan fuzzy logic dapat dilihat pada Gambar 1. 


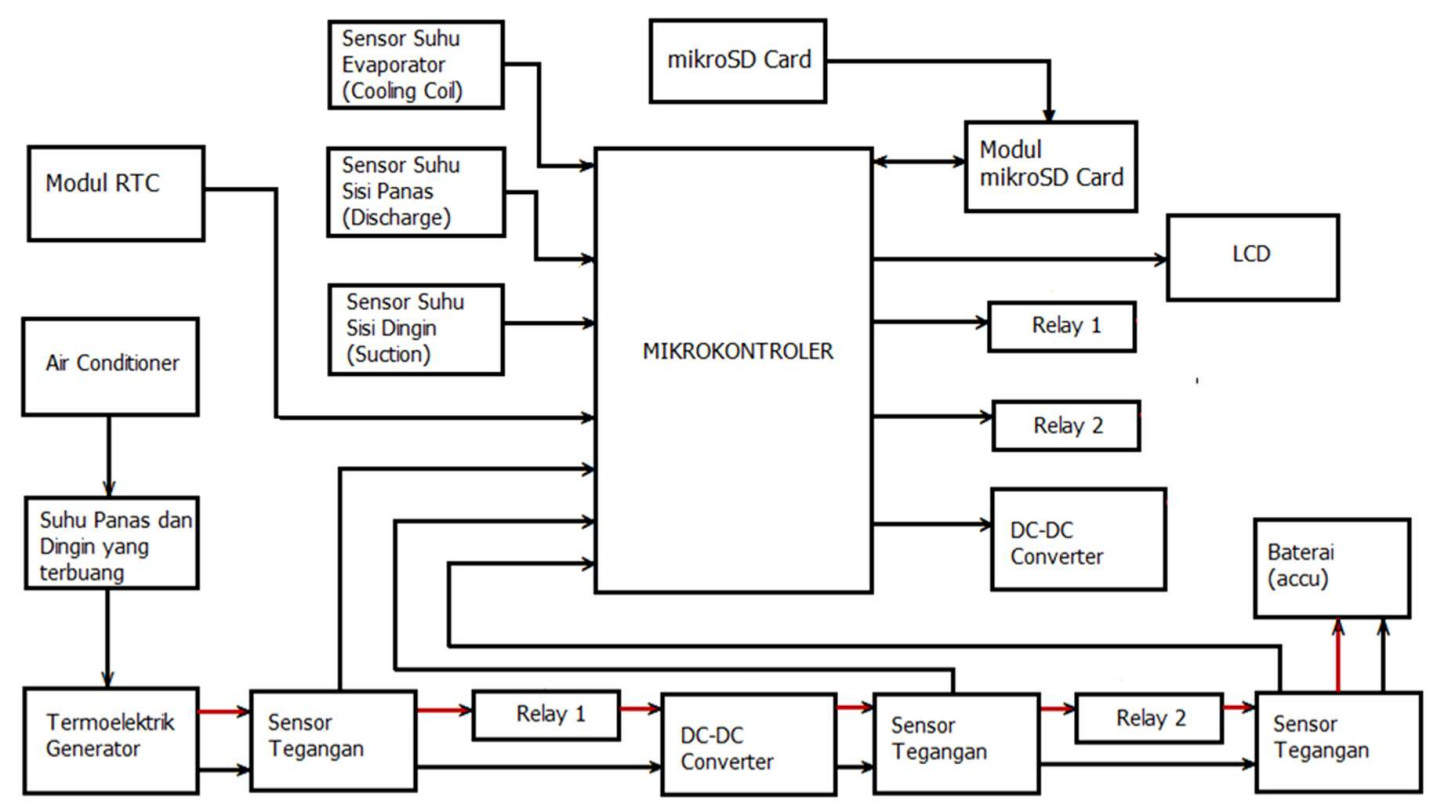

Gambar 1. Diagram Blok Sistem Termoelektrik Generator pada Air Conditioner

Komponen penyusun terdiri dari air conditioner yang telah dimodifikasi. Air conditioner akan menghasilkan panas dan dingin melalui proses kompresi kompresor dan sisa pendinginan ruangan. Panas dan dingin yang dihasilkan air conditioner dimanfaatkan termoelektrik generator.

Kontroler yang digunakan menggunakan board Arduino Uno. Bagian input mikrokontroler terdiri dari sensor suhu DS18B20, sensor tegangan, dan Modul RTC. Mikrokontroler akan membaca suhu pada sisi discharge, suction, dan evaporator. DC-DC konverter digunakan untuk mengatur tegangan yang dihasilkan termoelektrik generator, tegangan keluaran DC-DC konverter digunakan untuk pengisian Aki 6V 4,5 Ah.

Tegangan yang dihasilkan termoelektrik, tegangan output DC-DC konverter dan tegangan akumulator akan dibaca oleh mikrokontroler melalui sensor tegangan. Mikrokontroler akan memberikan sinyal PWM untuk pengontrolan tegangan DC-DC konverter melalui algoritma fuzzy logic. Relay digunakan untuk memberikan kontrol input minimal pada DC-DC konverter dan akumulator. Parameter penelitian berupa nilai suhu dan tegangan akan ditampilkan melalui LCD, dan akan dicatat otomatis melalui kartu microSD secara real time.

\subsubsection{Air Conditioner}

Air conditioner yang digunakan pada penelitian ini adalah air conditioner jenis split wall mounted dengan kapasitas pendinginan 9000 Btu/hr (1 PK). Air conditioner tersebut akan menghasilkan panas yang terbuang pada saat beroperasi, panas yang terbuang tersebut akan dimanfaatkan termoelektrik generator untuk menjadi energi listrik. Bentuk fisik air conditioner dapat dilihat pada Gambar 2, sedangkan spesifikasi dari air conditioner dapat dilihat pada Tabel 1. 


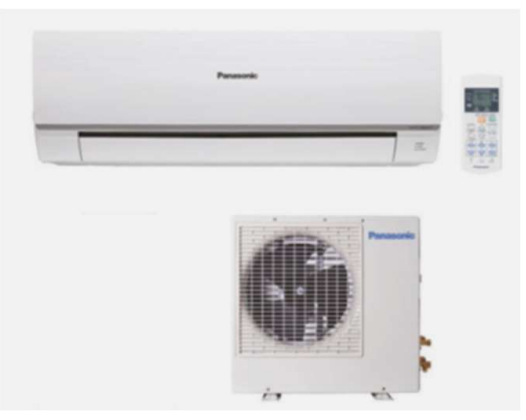

Gambar 2. Bentuk Fisik Air Conditioner
Tabel 1. Spesifikasi Air Conditioner

\begin{tabular}{|c|c|}
\hline Jenis Spesifikasi & Keterangan \\
\hline Merk & Panasonic \\
\hline Model No & CU 09 KKP \\
\hline Volt & $220-240 \mathrm{~V} ~$ \\
\hline Frequensi & $50 \mathrm{~Hz}$ \\
\hline Max input & $1,12 \mathrm{Kw} / 4,9 \mathrm{~A}$ \\
\hline KapasitasPendinginan & $9540-9720 \mathrm{Kj} / \mathrm{h}$ \\
\hline Arus & $3,8-3,9 \mathrm{~A}$ \\
\hline Refrigeran & $\mathrm{R} 22$ \\
\hline
\end{tabular}

\subsubsection{Termoelektrik Generator}

Termoelektrik generator adalah suatu pembangkit listrik yang memanfaatkan perbedaan suhu pada sisi termoelektrik menjadi energi listrik dengan efek seebeck. Termoelektrik generator yang digunakan pada penelitian ini adalah jenis termoelektrik TEC 12706 sebanyak 50 buah yang disusun secara seri. Bentuk fisik dari termoelektrik TEC 12706 dapat dilihat pada Gambar 3, sedangkan spesifikasi termoelektrik TEC 12706 dapat dilihat pada Tabel 2.

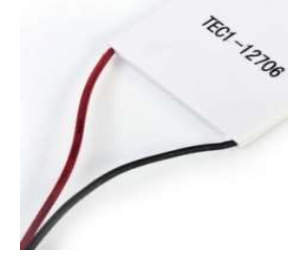

Gambar 3. Bentuk Fisik Termoelektrik
Tabel 2. Spesifikasi Termoelektrik TEC-12706

\begin{tabular}{|c|c|}
\hline Jenis Spesifikasi & Keterangan \\
\hline$P$ - $N$ Couples & 127 \\
\hline $\operatorname{Imax}(A)$ & 6,1 \\
\hline $\operatorname{Vmax}(V)$ & 16 \\
\hline$\Delta \operatorname{Tmax}(\mathcal{C})$ & 70 \\
\hline Heat flow $(W)$ & 61,4 \\
\hline Resistansi $(\Omega)$ & 13,2 \\
\hline
\end{tabular}

\subsection{Modifikasi Air Conditioner}

Bagian air conditioner standar terdiri dari bagian indoor unit dan outdoor unit. Bagian indoor unit terdiri dari evaporator, blower, dan kontrol suhu. Bagian outdoor unit terdiri dari kompresor, kondensor dengan kipas, filter drier, dan pipa kapiler seperti yang terlihat pada Gambar 4a. Prinsip pendinginan ruangan yang dilakukan air conditioner merupakan prinsip dari refrigerasi kompresi uap. Agar termoelektrik generator dapat diaplikasikan pada air conditioner, dilakukan modifikasi pada outdoor unit. Modifikasi dilakukan dengan menambahkan modul termoelektrik diantara jalur tekanan tinggi (discharge line) dan jalur tekanan rendah (suction line). Suhu discharge line akan cenderung panas dikarenakan proses kompresi refrigeran yang dilakukan kompresor. Sedangkan suhu suction line akan akan cenderung dingin dikarenakan sisa proses pendinginan ruangan. Rancangan termoelektrik generator yang dibuat dapat dilihat pada Gambar 4b. 


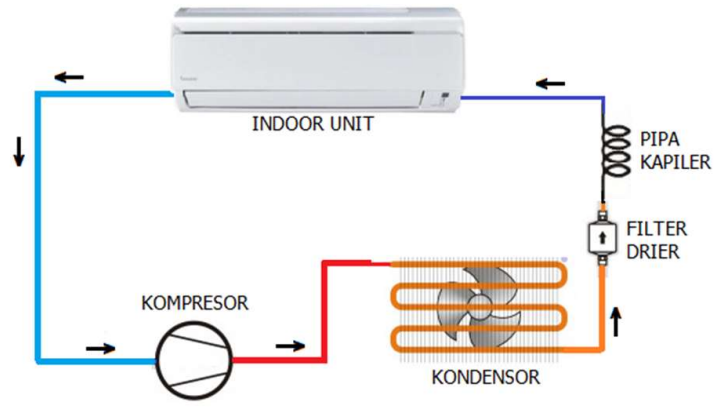

(a)

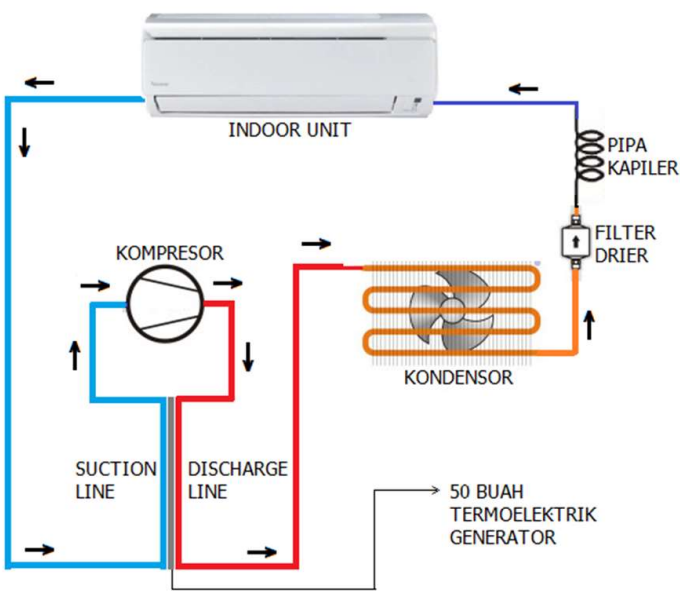

(b)

Gambar 4. (a) Kondisi AC Sebelum Modifikasi (b) Kondisi AC Setelah Modifikasi

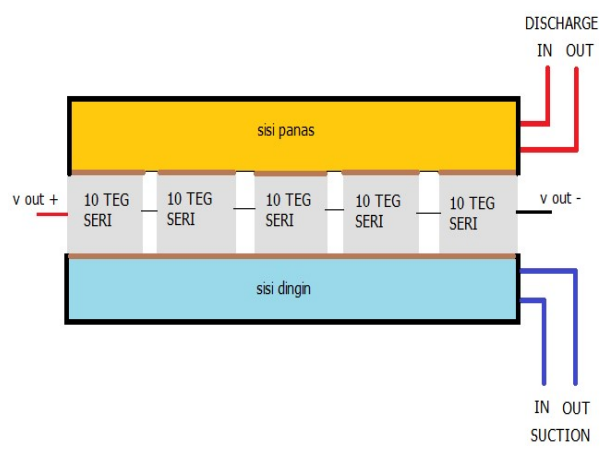

(a)

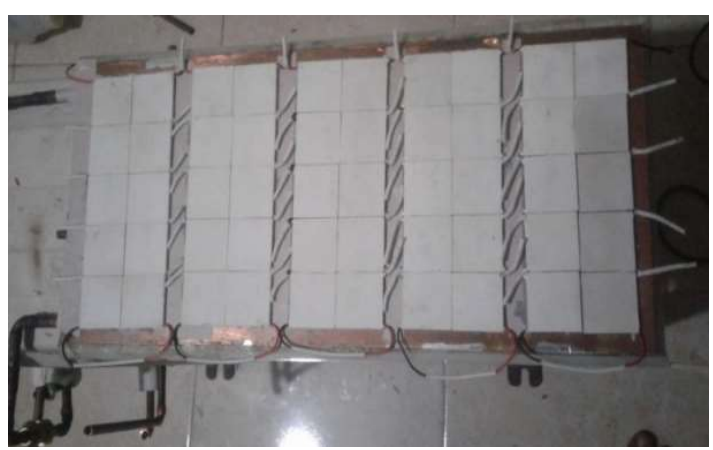

(b)

\section{Gambar 5. (a) Desain Konfigurasi 50 Buah Termoelektrik Generator (b) Realisasi Konfigurasi Termoelektrik Generator}

Modul termoelektrik yang digunakan sebanyak 50 buah, dengan konfigurasi seri. Seperti pada Gambar 5a sumber panas termoelektrik generator mengambil panas dari discharge line. Pada sisi panas tersebut terpasang plat tembaga dengan tebal $1,8 \mathrm{~mm}$ yang berhubungan langsung dengan sisi panas termoelektrik generator dan sisi dari discharge line dengan insulasi polyurethane foam. Sisi dingin termoelektrik generator mengambil dingin dari suction line. Pada sisi dingin tersebut juga terpasang plat tembaga dengan tebal 1,8 $\mathrm{mm}$ yang berhubungan langsung dengan sisi dingin termoelektrik generator dan sisi suction line dengan insulasi polyurethane foam. Realisasi Konfigurasi 50 buah termoelektrik generator dapat dilihat pada Gambar 5b, modifikasi dilakukan pada air conditioner yaitu pada bagian outdoor unit. 
Perancangan Pembangkit Listrik Termoelektrik pada Proses Refrigerasi Air Conditioner dengan Metode Fuzzy Logic

\subsection{DC-DC Konverter}

Jenis DC-DC konverter yang digunakan berupa buck converter. Jenis ini dipilih agar tegangan keluaran dapat di turunkan menjadi lebih rendah dari tegangan masukan. Konverter yang digunakan memiliki spesifikasi.

Tabel 3. Spesifikasi DC-DC Konverter

\begin{tabular}{|c|c|}
\hline Jenis Spesifikasi & Keterangan \\
\hline Tegangan masukan & $4-45 \mathrm{~V}$ \\
\hline Arus masukan & Max 3 Ampere \\
\hline Tegangan keluaran & $1,25-35 \mathrm{~V}$ \\
\hline Arus Keluaran & Max 3 Ampere \\
\hline Frekuensi & $150 \mathrm{KHz}$ \\
\hline Effisiensi & Max $92 \%$ \\
\hline Dimensi & $43 \mathrm{~mm} \times 21 \mathrm{~mm} \times 14 \mathrm{~mm}$ \\
\hline
\end{tabular}

Tegangan keluaran dari DC-DC konverter ini diatur dengan cara mengubah nilai PWM dari mikrokontroler Arduino yang dihubungkan kerangkaian low pass filter dan rangkaian Op-Amp untuk mendapatkan tegangan kerja dari 0 - 5 Volt, lalu tegangan outputOp-Amp dihubungkan ke rangkaian pembagi tegangan agar tegangan output sesuai dengan tegangan referensi feedback pada DC-DC konverter pada datasheet IC LM2596.

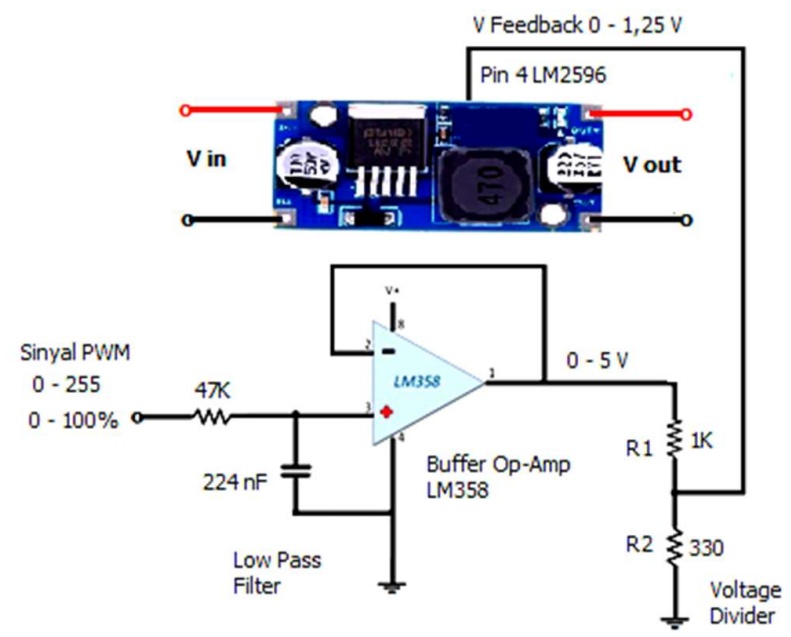

Gambar 6. Pengaturan Tegangan Output DC-DC Konverter dengan PWM Mikrokontroler

\subsection{Perancangan Perangkat Lunak}

Perancangan perangkat lunak dilakukan untuk mengontrol tegangan keluaran termoelektrik generator. Sistem kontrol yang digunakan dengan algoritma fuzzy logic. Pengendali logika fuzzy digunakan sistem kontrol loop tertutup seperti yang terlihat pada Gambar 7, keluaran kontroler logika fuzzy merupakan nilai PWM yang digunakan untuk mengatur tegangan DCDC konverter. Input masukan fuzzy merupakan nilai error dan delta error. Nilai error merupakan selisih antara tegangan keluaran aktual dengan tegangan set poin. Delta error merupakan selisih error sekarang dengan error sebelumnya. 


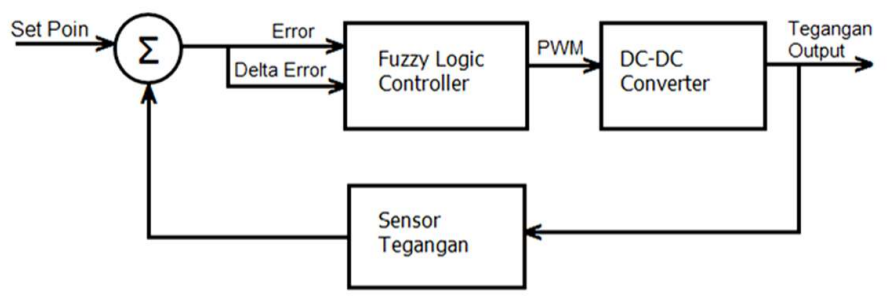

\section{Gambar 7. Diagram Blok Fuzzy Logic Controller pada DC-DC Konverter}

Pemetaan fungsi keanggotaan input error dan delta error dibagi menjadi 5 fungsi keanggotaan yaitu $\mathrm{N}$ =negatif, $\mathrm{NK}=$ negatif kecil, $\mathrm{Z}=\mathrm{zero}, \mathrm{PK}=$ positif kecil dan $\mathrm{P}=$ positif. Sedangkan pemetaan fungsi keanggotaan output dibagi menjadi 5 fungsi keanggotaan yaitu $\mathrm{K}=$ kecil, $\mathrm{AK}=$ agak kecil, $\mathrm{S}=$ sedang, $\mathrm{AB}=$ agak besar dan $\mathrm{B}=$ besar. Penentuan fungsi keanggotaan input dilakukan untuk merubah nilai crisp input menjadi masukan fuzzy.

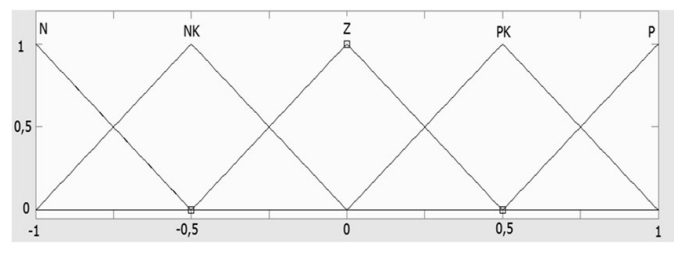

(a)

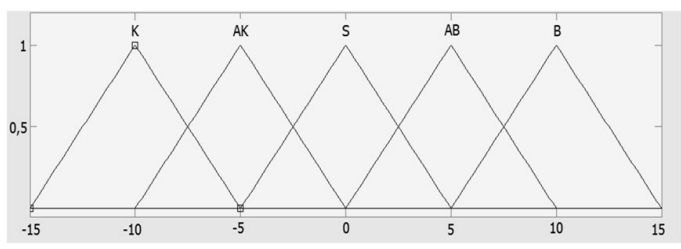

(b)

\section{Gambar 8. (a) Fungsi Keanggotaan Input Error dan Delta Error (b) Fungsi Keanggotaan Output PWM}

Setelah ditentukan fuzzy setmasukan error dan delta error, kemudian sistem diberikan aturanaturan terhadap antecendent untuk menentukan keluaran yang diharapkan. Sedangkan evaluasi rule yang dibuat dapat dilihat pada Tabel 4.

Tabel 4. Evaluasi Rule

\begin{tabular}{|c|c|c|c|c|c|}
\hline $\begin{array}{l}\text { Error } \\
\text { D_error }\end{array}$ & N & NK & Z & PK & P \\
\hline $\mathbf{N}$ & K & K & AK & AK & S \\
\hline NK & K & AK & S & S & AB \\
\hline Z & AK & S & S & S & AB \\
\hline PK & AK & S & S & AB & B \\
\hline P & S & AB & AB & B & B \\
\hline
\end{tabular}

Setelah ditentukan evaluasi rule, lalu selanjutnya dilakukan defuzzifikasi, untuk merubah nilai fuzzy output menjadi nilai crisp output. Defuzzifikasi pada penelitian ini dilakukan dengan metode Weigheted Average Area. Metode ini sering digunakan di aplikasi fuzzy dikarenakan lebih effisien perhitungannya (Morim, dkk, 2017). Metode weighted average area dituliskan dengan rumus:

$$
Z^{*}=\frac{\sum \mu c(\bar{z}) \cdot(\overline{\mathbf{z}})}{\sum \mu c(\overline{\mathbf{z}})}
$$

Dimana:

$Z^{*} \quad$ : Crisp Output (PWM Fuzzy)

$\bar{Z} \quad$ : Titik tengah tiap fungsi keanggotaan 
Perancangan Pembangkit Listrik Termoelektrik pada Proses Refrigerasi Air Conditioner dengan Metode

$\mu c(\bar{z}) \quad$ : Nilai DOM untuk pada saat $z=\bar{Z}$

\subsubsection{Flow Chart}

Diagram alir pemrograman sistem dilakukan sesuai Gambar 9.

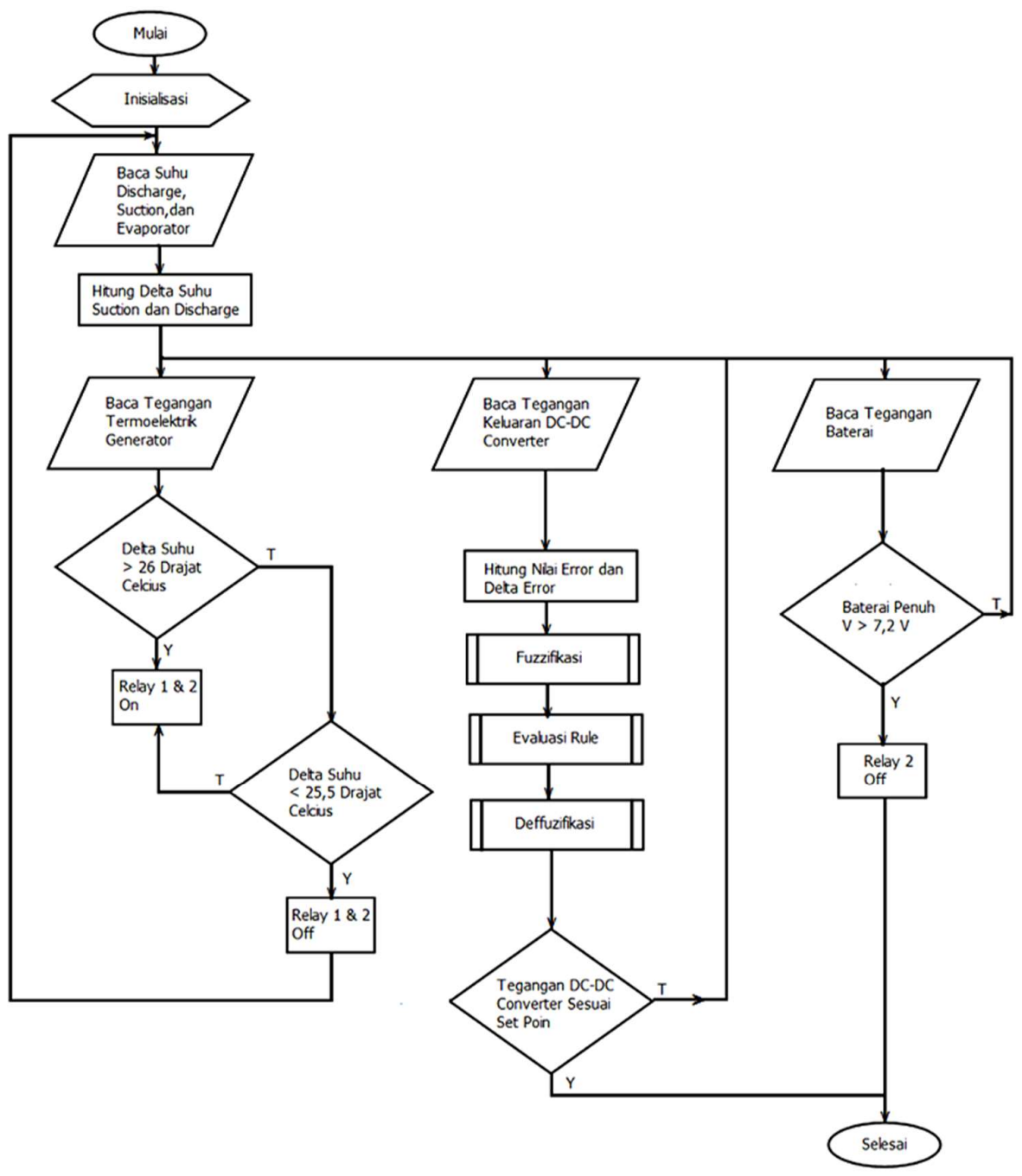

Gambar 9. Diagram Alir Program Utama

Ketika dimulai program akan melakukan inisialisasi, lalu program akan membaca nilai suhu discharge, suction, evaporator, dan menghitung delta suhu, setelah itu program akan membaca tegangan termoelektrik generator, tegangan output DC-Dc konverter dan tegangan akumulator.

Ketika delta suhu sudah lebih dari $26^{\circ} \mathrm{C}$ maka relay akan on, untuk memberikan tegangan input pada DC-DC konverter dengan supply tegangan termoelektrik generator.

Sistem akan melakukan pengontrolan tegangan output DC-DC konverter dengan proses fuzzifikasi menghitung nilai error dan delta error, lalu proses evaluasi rule, dan proses defuzzifikasi dengan crisp output berupa pengontrolan nilai PWM agar mendapatkan tegangan sesuai set poin. Set poin tegangan pada output DC-DC konverter adalah 7,2 Volt dikarenakan 
baterai yang digunakan untuk menyimpan tegangan termoelektrik generator adalah akumulator (aki) 6 V 4,5 Ah.

Tegangan output DC-DC konverter akan digunakan untuk pengisian baterai (aki). Sistem akan membaca tegangan baterai, jika tegangan baterai sudah penuh (melebihi set poin) maka relay akan off. Nilai variabel yang diperlukan akan disimpan pada kartu microSD dan ditampilkan ke layar LCD.

\section{HASIL DAN PEMBAHASAN}

Setelah perancangan pembangkit listrik termoelektrik pada air conditioner telah direalisasikan, maka dilakukan pengujian untuk mengetahui unjuk kerja dari sistem yang telah dibuat. Hasil akhir dari air conditioner yang telah dimodifikasi dengan termoelektrik generator dapat dilihat pada Gambar 10. Untuk pengujian dilakukan dengan pengujian performa suhu air conditioner, pengujian tegangan open circuit termoelektrik generator, pengujian keseluruhan, dan pengujian pengisian arus akumulator.

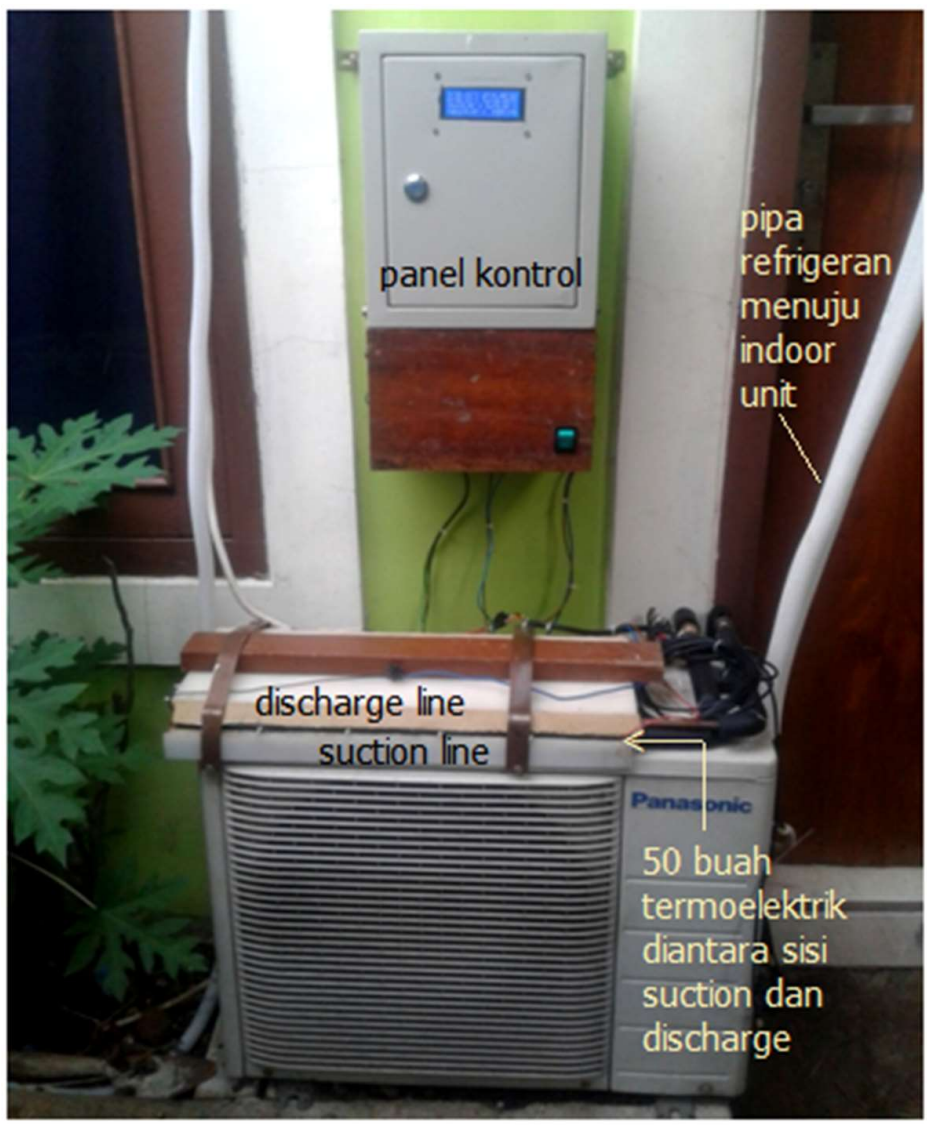

Gambar 10. Hasil Modifikasi Termoelektrik Generator pada Air Conditioner

\subsection{Pengujian Performa Suhu Air Conditioner}

Pengujian performa air conditioner dilakukan sebanyak 2 kali, yaitu pada pagi hari dan malam hari. Tujuan dari pengujian ini adalah untuk mengetahui suhu yang dihasilkan air conditioner antara sisi panas (discharge), sisi dingin (suction), dan evaporator (cooling coil) setelah dimodifikasi dengan termoelektrik generator. Air conditioner dinyalakan dan di set dengan 
Perancangan Pembangkit Listrik Termoelektrik pada Proses Refrigerasi Air Conditioner dengan Metode Fuzzy Logic

suhu ruangan $16^{\circ} \mathrm{C}$. Lalu pembacaan sensor suhu disimpan menggunakan modul microSD card. Hasil pengujian dapat dilihat pada Gambar 11.
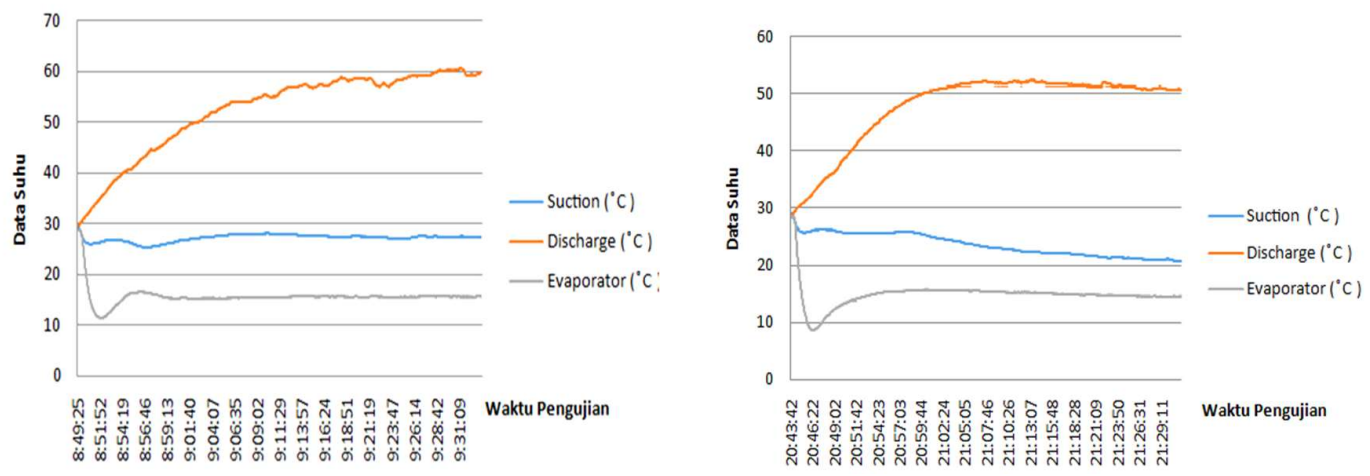

Gambar 11. Grafik Performa Suhu Air Conditioner

Dari Gambar 11 didapatkan bahwa suhu discharge line terus meningkat berdasarkan waktu dengan suhu maksimal discharge line adalah $60^{\circ} \mathrm{C}$. Suhu suction line dapat mencapai $30^{\circ} \mathrm{C}$ sampai dengan $22^{\circ} \mathrm{C}$. Dengan suhu evaporator dapat stabil di kisaran $15^{\circ} \mathrm{C}$. Dinginnya suhu evaporator menandakan penggunaan termoelektrik generator pada air conditioner tidak mengganggu proses pendinginan ruangan.

\subsection{Pengujian Tegangan Open Circuit Termoelektrik Generator}

Setelah dilakukan pengujian performa suhu air conditioner, dilakukan pengujian tegangan open circuit termoelektrik generator. Air conditioner dinyalakan dan di set dengan suhu ruangan $16^{\circ} \mathrm{C}$, lalu tegangan keluaran termoelektrik generator dan suhu air conditioner dibaca oleh mikrokontroler melalui sensor, lalu datanya disimpan menggunakan modul microSD card. Hasil yang didapatkan dapat dilihat pada Gambar 12 dan data sample pengujian dapat dilihat pada Tabel 5.

Tabel 5. Pengujian Tegangan Termoelektrik dan Delta Suhu

\begin{tabular}{|c|c|c|c|}
\hline No & $\begin{array}{c}\text { Delta } \\
\text { Suhu }\left({ }^{\circ} \mathrm{C}\right)\end{array}$ & $\begin{array}{c}\text { Tegangan } \\
\text { Termoelektrik (Volt) }\end{array}$ & $\begin{array}{c}\text { Koefisien } \\
\text { Seebeck }\left(V /{ }^{\circ} \mathrm{C}\right) \\
\end{array}$ \\
\hline 1 & 0.44 & 0.07 & 0.15909 \\
\hline 2 & 4.13 & 2.61 & 0.63196 \\
\hline 3 & 9.44 & 3.04 & 0.32203 \\
\hline 4 & 11.88 & 4.00 & 0.33670 \\
\hline 5 & 13.88 & 5.23 & 0.37680 \\
\hline 6 & 14.88 & 6.07 & 0.40793 \\
\hline 7 & 17.44 & 7.10 & 0.40711 \\
\hline 8 & 20.81 & 8.13 & 0.39068 \\
\hline 9 & 22.62 & 9.06 & 0.40053 \\
\hline 10 & 24.50 & 10.05 & 0.41020 \\
\hline 11 & 25.87 & 11.15 & 0.43100 \\
\hline 12 & 27.00 & 12.18 & 0.45111 \\
\hline 13 & 29.12 & 13.12 & 0.45055 \\
\hline 14 & 30.75 & 13.98 & 0.45463 \\
\hline 15 & 30.94 & 14.01 & 0.45281 \\
\hline 16 & 31.87 & 14.22 & 0.46776 \\
\hline 17 & 32.38 & 14.27 & 0.41916 \\
\hline \multicolumn{3}{|c|}{ Total Koefisien Seebeck (V/ $\left.{ }^{\text {C }}\right)$} & 6,97 \\
\hline \multicolumn{3}{|c|}{ Rata-Rata Koefisien Seebeck $\left(\mathrm{V} /{ }^{\circ} \mathrm{C}\right)$} & 0,41 \\
\hline
\end{tabular}



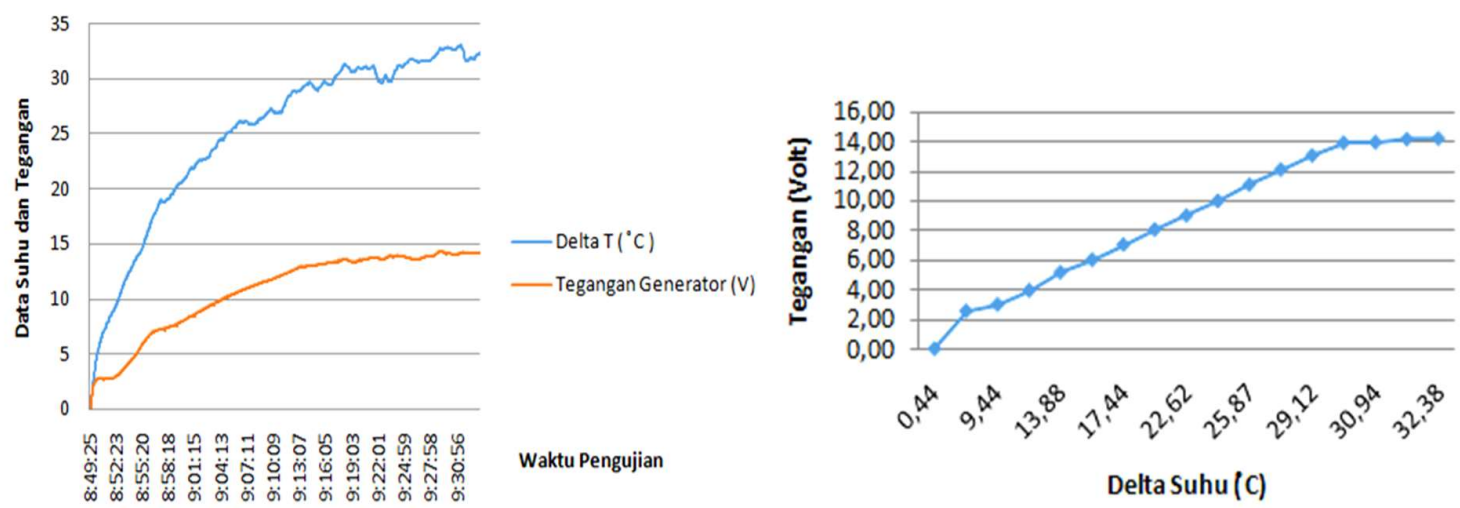

Gambar 12. Grafik Tegangan Termoelektrik dan Delta Suhu

Dari Gambar 12 didapatkan bahwa delta suhu meningkat seiring berjalannya waktu pengujian, dengan maksimal delta suhu berkisar $30^{\circ} \mathrm{C}$ sampai dengan $33^{\circ} \mathrm{C}$. Semakin tinggi delta suhu, maka semakin tinggi pula tegangan termoelektrik yang dihasilkan.

Pada pengujian tegangan open circuit termoelektrik generator dapat dihitung koefisien seebeck dengan persamaan (Ma, Wang, \& Yang, 2014):

Dimana:

$$
\alpha=\frac{V o}{\Delta T}
$$

$\alpha \quad$ : koefisien seebeck $\left(\mathrm{V} /{ }^{\circ} \mathrm{C}\right)$

$\Delta T \quad$ : delta suhu sisi panas dan sisi dingin $\left({ }^{\circ} \mathrm{C}\right)$

$V o \quad$ : tegangan output generator (V)

Contoh perhitungan koefisien seebeck pada data Tabel 5 no 2 adalah sebagai berikut:

$$
\alpha=\frac{2,61}{4,13}=0,63196 \mathrm{~V} /{ }^{\circ} \mathrm{C}
$$

Contoh perhitungan koefisien seebeck pada delta suhu $32,38{ }^{\circ} \mathrm{C}$ adalah sebagai berikut:

$$
\alpha=\frac{14,27}{32,38}=0,41916 \mathrm{~V} /{ }^{\circ} \mathrm{C}
$$

Nilai koefisien seebeck pada pengujian berbeda dikarenakan karakteristik material termoelektrik yang berubah sesuai dengan perubahan delta temperatur pada termoelektrik (Ma, Wang, \& Yang, 2014).

Dari hasil pengujian pada Tabel 5 dapat dilihat tegangan open circuit maksimal termoelektrik generator adalah 14,27 Volt dengan delta suhu $32,38{ }^{\circ} \mathrm{C}$ dengan nilai koefisisen seebeckadalah $0,419 \mathrm{~V} /{ }^{\circ} \mathrm{C}$.

\subsection{Pengujian Keseluruhan}

Pengujian sistem keseluruhan adalah pengujian termoelektrik generator dengan fuzzy logic controller dengan menggunakan beban baterai (aki) $6 \mathrm{~V} 4.5$ Ah. Pengujian ini menggunakan buck converter yang diatur dengan algoritma fuzzy. Agar tegangan keluaran yang sesuai dengan tegangan minimal pengisian baterai. Diberikan kontrol on-off relay tegangan output termoelektrik generator untuk buck converterpada delta suhu minimal $26^{\circ} \mathrm{C}$ dikarenakan saat pembebanan saat delta suhu dibawah $25^{\circ} \mathrm{C}$ tegangan termoelektrik turun setengah dari tegangan open circuit nya. Hasil pengujian sistem keseluruhan ditunjukan pada Gambar 13. 
Perancangan Pembangkit Listrik Termoelektrik pada Proses Refrigerasi Air Conditioner dengan Metode Fuzzy Logic

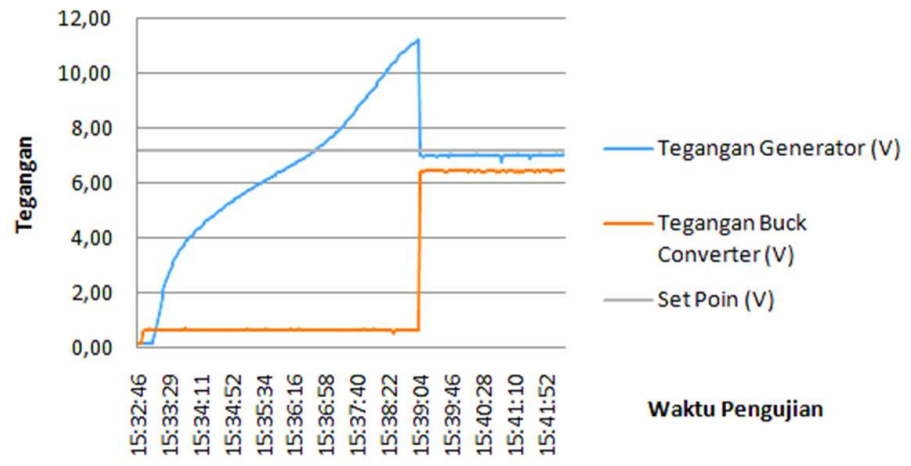

Gambar 13. Grafik Tegangan Termoelektrik dan Buck Converter

Pada grafik Gambar 13 dapat dilihat tegangan termoelektrik generator turun dari $11 \mathrm{~V}$ ke 7 Volt saat delta temperatur $26^{\circ} \mathrm{C}$ (relay aktif on). Saat relay on tegangan output termoelektrik generator stabil di angka 7 Volt dan tegangan output buck converter juga stabil yaitu 6.4 Volt.

Karakteristrik respon sistem pada Gambar 13 didapatkan.

$\begin{array}{ll}\text { Rise time } & : 5 \text { Menit } 51 \text { detik } \\ \text { Delay time } & : 6 \text { menit } 18 \text { detik } \\ \text { Settling time } & : 6 \text { menit } 18 \text { detik } \\ \text { Error Steady State } & : 0,8\end{array}$

Waktu delay time tinggi dikarenakan tegangan termoelektrik generator yang diberikan untuk input buck converter di set menggunakan kontrol on-off relay dengan delta temperatur minimal termoelektrik generator diatas $26^{\circ} \mathrm{C}$. Sehingga pengontrolan tegangan terjadi pada saat delta temperatur termoelektrik generator diatas $26^{\circ} \mathrm{C}$.

\subsection{Pengukuran Arus Pengisisan Akumulator}

Saat pengujian keseluruhan saat rata-rata delta suhu diatas $30^{\circ} \mathrm{C}$ dilakukan pengukuran arus pengisian ke akumulator menggunakan multimeter. Dokumentasi saat pengukuran dapat dilihat dilihat pada Gambar 14a dan rangkaian pengukuran dapat dilihat pada Gambar 14b.

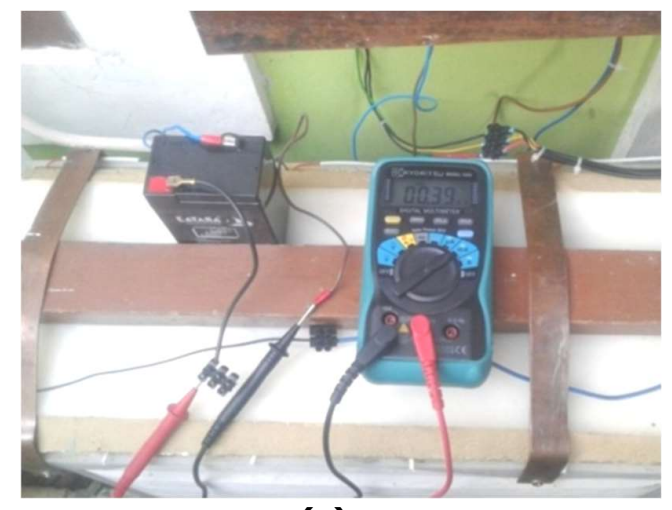

(a)

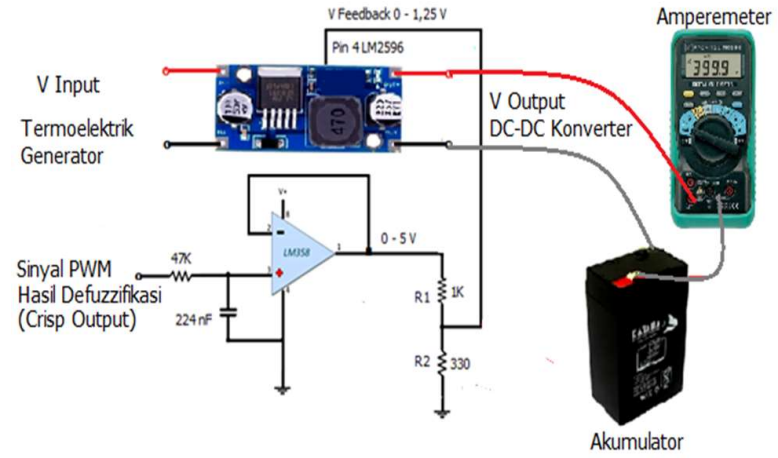

(b)

Gambar 14.(a) Pengujian Pengukuran Arus Pengisian Akumulator (b) Rangkaian Pengujian

Dari hasil pengukuran didapatkan Tabel 6 sebagai berikut. 
Tabel 6. Pengukuran Arus Pengisian Akumulator

\begin{tabular}{|r|c|c|}
\hline No & Delta Suhu ( ${ }^{\circ} \mathbf{C}$ ) & Pengukuran Arus (mA) \\
\hline 1 & 30.44 & 0.27 \\
\hline 2 & 30.56 & 0.29 \\
\hline 3 & 30.81 & 0.26 \\
\hline 4 & 31.00 & 0.25 \\
\hline 5 & 31.75 & 0.39 \\
\hline 6 & 31.94 & 0.38 \\
\hline 7 & 32.44 & 0.44 \\
\hline 8 & 33.38 & 0.43 \\
\hline 9 & 33.44 & 0.39 \\
\hline 10 & 33.56 & 0.28 \\
\hline 11 & 33.75 & 0.35 \\
\hline 12 & 33.94 & 0.21 \\
\hline 13 & 34.06 & 0.20 \\
\hline 14 & 34.13 & 0.39 \\
\hline 15 & 34.25 & 0.38 \\
\hline 16 & 34.31 & 0.39 \\
\hline \multicolumn{2}{|c|}{ Rata-Rata Arus (mA) } & 0.33 \\
\hline
\end{tabular}

Dari Tabel 6 membuktikan bahwa sistem dapat melakukan pengisian akumulator, dengan ratarata arus pengisisan akumulator pada saat delta suhu diatas $30^{\circ} \mathrm{C}$ adalah sebesar 0,33 mili Ampere.

\section{KESIMPULAN}

Berdasarkan hasil penelitian mengenai perancangan pembangkit listrik termoelektrik pada proses refrigerasi air conditioner dengan metode fuzzy logic didapatkan kesimpulan.

1. Penggunaan pembangkit listrik termoelektrik tidak mengganggu proses pendinginan ruangan hal ini dibuktikan dengan temperatur evaporator pada pengujian suhu air conditioner dapat mencapai $15^{\circ} \mathrm{C}$.

2. Tegangan open circuit termoelektrik generator dapat mencapai $14 \mathrm{~V}$ pada delta suhu $32,38^{\circ} \mathrm{C}$. Semakin tinggi delta suhu semakin tinggi pula tegangan open circuit termoelektrik generator.

3. Sistem pembangkit listrik termoelektrik yang telah dirancang pada pengujian keseluruhan diperoleh respon sistem dengan rise time 5 menit 51 detik, delay time 6 menit 18 detik, dengan steady state error 0,8 pada set poin 7,2 Volt.

4. Sistem pembangkit listrik termoelektrik dengan fuzzy logic yang telah dirancang dapat digunakan untuk pengisian sebuah akumulator $6 \mathrm{~V} 4.5$ Ah dengan tegangan output kontroler stabil pada 6,4 $\mathrm{V}$ dan arus pengisian akumulator 0,33 mili Ampere pada saat delta suhu diatas $30^{\circ} \mathrm{C}$.

\section{DAFTAR RUJUKAN}

Majanasastra, R. B. S. (2015). Analisis Kinerja Mesin Pendingin Kompresi Uap Menggunakan FE-36. Jurnal Imiah Teknik Mesin, 3(1), 1-15. Retrieved from http://ejournal.unismabekasi.ac.id 
Perancangan Pembangkit Listrik Termoelektrik pada Proses Refrigerasi Air Conditioner dengan Metode Fuzzy Logic

Hermawan, I., \& Idris, I. (2014). Kajian Potensi Energi Panas Buangan Dari Air Conditioner ( Ac ). Jurnal Teknovasi, 01(2), 1-7.

Ma, Z., Wang, X., \& Yang, A. (2014). Influence of Temperature on Characters of Thermoelectric Generators Based on Test Bed. Journal of Nanomaterials, 2014. https://doi.org/10.1155/2014/719576

Morim, A., Sa Fortes, E., Reis, P., Cosenza, C., Doria, F., \& Goncalves, A. (2017). Think Fuzzy System : Developing New Pricing Strategy Methods for Consumer Goods Using Fuzzy Logic. International Journal of Fuzzy Logic Systems, 71$)$, 1-17. https://doi.org/10.5121/ijfls.2017.7101

Negash, A. A., Kim, T. Y., \& Cho, G. (2017). Effect of Electrical Array Configuration of Thermoelectric Modules on Waste Heat Recovery of Thermoelectric Generator. Sensors and Actuators, A: Physical, 260, 212-219. https://doi.org/10.1016/j.sna.2017.04.016

Puspita, S. C., Sunarno, H., \& Indarto, B. (2017). Generator Termoelektrik untuk Pengisisan Aki. Jurnal Fisika Dan Aplikasinya, 13(2), 84. https://doi.org/10.12962/j24604682.v13i2.2748

Remeli, M. F., Kiatbodin, L., Singh, B., Verojporn, K., Date, A., \& Akbarzadeh, A. (2015). Power Generation from Waste Heat Using Heat Pipe and Thermoelectric Generator. Energy Procedia, 75, 645-650. https://doi.org/10.1016/j.egypro.2015.07.477

Ryanuargo, Anwar, S., \& Sari, S. P. (2013). Generator Mini dengan Prinsip Termoelektrik dari Uap Panas Kondensor pada Sistem Pendingin. Jurnal Rekayasa Elektrika, 1044), 180185. https://doi.org/10.17529/jre.v10i4.1108

Sari, S. P. (2019). Analisis Energi Listrik Dari Panas Kondensor Air Conditioner Dengan Insulasi Dan Generator Termoelektrik. Jurnal Asiimetrik, 1, 65-73.

Sreekala, P., \& Ramkumar, A. (2019). Performance Analysis of Thermo Electric Generator using MATLAB. International Journal of Recent Technology and Engineering, 8(4S2), 362365. https://doi.org/10.35940/ijrte.d1081.1284s219

Zhang, X., \& Zhao, L. D. (2015). Thermoelectric materials: Energy Conversion Between Heat and Electricity. Journal of Materiomics, 1(2), 92-105. https://doi.org/10.1016/j.jmat.2015.01.001

Zheng, X. F., Liu, C. X., Yan, Y. Y.,\& Wang, Q. (2014). A Review of Thermoelectrics Research - Recent Developments and Potentials for Sustainable and Renewable Energy Applications. Renewable and Sustainable Energy Reviews, 32, 486-503. https://doi.org/10.1016/j.rser.2013.12.053 